\title{
Distribution of Natural and Anthropogenic Sources, and Mapping of As, Co, and Hg by Three Ecological Risk Indices in the Mid-continent of the USA
}

\author{
Almesleh Najwah Alssaeidi Ahmed ${ }^{1, ~ *}$, Philip Goodell, ", Ziwu Felix Dziedzorm ${ }^{2, ~ *}$, Kappus Eric ${ }^{3, *}$ \\ ${ }^{1}$ Program of Environmental Science \& Engineering, University of Texas at El Paso, El Paso, USA \\ ${ }^{2}$ Department of Geological Science, University of Texas at El Paso, El Paso, USA \\ ${ }^{3}$ General Education, Southwest University, El Paso, USA
}

Email address:

Fesca2003@gmail.com (A. N. A. Ahmed)

${ }^{*}$ Corresponding author

\section{To cite this article:}

Almesleh Najwah Alssaeidi Ahmed, Philip Goodell, Ziwu Felix Dziedzorm, Kappus Eric. Distribution of Natural and Anthropogenic Sources, and Mapping of As, Co, and Hg by Three Ecological Risk Indices in the Mid-continent of the USA. American Journal of Environmental Science and Engineering. Vol. 5, No. 2, 2021, pp. 35-52. doi: 10.11648/j.ajese.20210502.13

Received: May 2, 2021; Accepted: May 28, 2021; Published: July 9, 2021

\begin{abstract}
Three indicators are employed including the Enrichment factor (EF), geoaccumulation (I geo), and potential ecological risk assessment (PERI) to measure the degree of contamination of As, $\mathrm{Co}$, and $\mathrm{Hg}$ in soils. The objective of this investigation is to evaluate the concentration of As, Co, and $\mathrm{Hg}$ in the soils of Iowa (IA), Kansas (KS), and Nebraska (NE). Study of the spatial distribution of chemicals was carried out as part of the investigation, which leads to the suggestion of the potential source of the elements. EF, I geo and PERI indexes, As and Co contain minimal enrichment, and $\mathrm{Hg}$ is high. EF of As and $\mathrm{Hg}$ are similarly classified with minimal contamination as well as EF of Co in NE. EF can be ordered $\mathrm{Hg}>\mathrm{As}>\mathrm{Co}$. PERI values of As and $\mathrm{Co}$ are classified as a low risk. PERI values of $\mathrm{Hg}$ are higher than As and $\mathrm{Co}$. I geo values of As and Co indicate uncontaminated to moderately contaminated soil. I geo of $\mathrm{Hg}$ is highest of three chemicals order $\mathrm{Hg}>\mathrm{As}>\mathrm{Co}$. However, I geo degree of As is approximately similar in the three states and it is higher than $\mathrm{Co}$, which indicate as uncontaminated to moderately contaminated. PERI show serious ecological risk pollution of $\mathrm{Hg}$ in the soils. These investigations indicate minimal to moderate soil contamination with As and Co in the three states. The spatial distribution is widespread and continuous. Point source maps are compared with this present product. The nature of the spatial distribution correlates with the major human activity on the land, agriculture. The As, Co, and $\mathrm{Hg}$ chemistry of the soil is due to the intense fertilization that accompanies such successful agriculture, which originates from anthropogenic sources that require continuous monitoring.
\end{abstract}

Keywords: Chemical Elements, Soil Contamination, PERI, EF, I Geo, Regional Geochemical Mapping (RGM)

\section{Introduction}

In the last decades, soil sustainability and soil contamination with chemical elements has received more attention and become of global environmental concern [43]. Soil is the basis for the growth of different species of plants required for the food chain of living organisms. It is also the home of a large mass of microorganisms. Chemical elements in the soil have been found with low concentrations in rocks and soil [64]. Some of these elements such as As, Se are found as anions, while others such as $\mathrm{Cd}, \mathrm{Cr}, \mathrm{Cu}, \mathrm{Hg}, \mathrm{Ni}, \mathrm{Pb}$, and $\mathrm{Zn}$ occur as cations [64]. The increase of concentrations of chemical elements may accumulated overtime and cause soil pollution [46].

The need to identify the contaminated land areas and health risk assessments has given rise to variety activities in the agricultural geochemical environment. Soil properties vary spatially according to many factors such as geographic, and geologic locations, chemical composition, physical properties, and climate conditions, in addition to intentional addition of chemical elements such as fertilizer, pesticides, agricultural additives and other modified compounds, which impact physical, chemical, and biological properties, and functioning of the soil microbial biogenesis, soil fertility, and human 
health [6]. Sorption and degradation of the contaminants such as pesticides on the soil are dependent on the soil properties such as soil mineralogy, organic matter content, chemical compounds, $\mathrm{pH}$, moisture levels, and temperature [41].

The concentrations of chemical elements sometimes may exceed the recommended amount levels by the Environmental Protection Agency (EPA) and can cause damage to plants and create problems for both humans and animals. Understanding the differences between the natural concentration sources and anthropogenic impacts of chemical elements is required to determine the quality and the health of the soil [64]. Currently, agriculture practices may reduce soil biodiversity because the overuse of chemicals may lead to adverse ecological alterations [6].

This study focuses on chemical elemental loads in the mid-continent of USA. The overall objective of this study is to determine the spatial patterns of potentially contaminated soil with chemical elements using different pollution indices. The goal of this study is to estimate the enrichment of chemical elements including $\mathrm{As}, \mathrm{Co}$, and $\mathrm{Hg}$ in the soil in Iowa (IA), Nebraska (NE), and Kansas (KS). The measurement of potential chemical cumulative loading is performed using previously proposed contamination indices: (1) enrichment factor (EF), (2) geoaccumulation (I geo) index, and (3) potential ecological risk index (PERI), which can provide the opportunity to evaluate the long-term pollution. The data are used for: 1) Compare the special distribution and concentrations of the chemical elements, 2) calculating the EF, I geo, and PERI as a test of soil contamination by anthropogenic applications, 3) test if high values of EF, I geo, and PERI can be associated to known pollution sources.

\section{Materials and Methods}

\subsection{Study Area and Site Description}

The study area is in mid-continent of USA as shown in Figure 1. The states IA, KS, and NE are the target of this study to evaluate the chemical loading. Some regions have high chemical concentrations as shown in Figure 6 ( $a, b$, and $c)$. The study area is an agricultural region, and the farmland covers $99 \%$ of IA and more than half of NE and KS. The intense agricultural productivity in this region results in many agricultural factories and processing plants, specifically ones devoted to animals and processing of animals to prepare them to the human consumption. IA is one the of agriculturally most industrial areas in USA. In KS, food processing is the second activity in the state includes flour-milling, animal feed, meat-packing plants. The largest industry in NE is food manufacturing including meat processing [60].

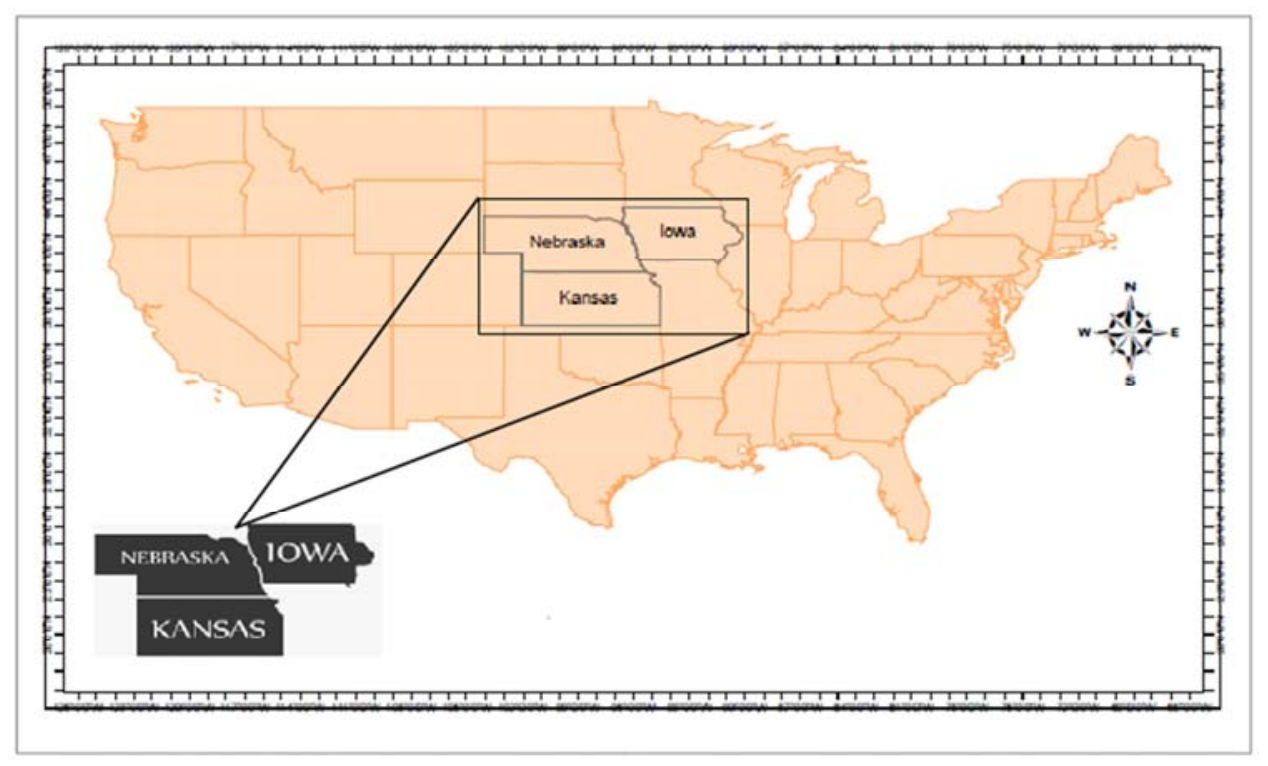

Figure 1. Map of study area includes Iowa (IA), Kansas (KS), and Nebraska (NE) (ArcGIS software) shows three states labelled map (www.vectorstock.com).

\subsection{Climate of the Area}

In the study area, the average annual temperature in IA, KS, and $\mathrm{NE}$ is $45^{\circ} \mathrm{C}$. Temperature overall is colder in the north and warmer in the south. There is more rain in the east than the west [41].

The annual average of precipitation is approximately 34 inches in IA, 28.9 in KS, and 23.6 in NE [19].

\subsection{Soil Types}

The Tama soil is categorized as a fine silty, mixed, super active, mesic typic Argiudolls. In IA, topsoil and subsoil are formed from silty clay loam and loess is silt and clay particles [60]. Topsoil layer is granular and has an excellent drainage. Soil in IA is very productive for plant growth [60]. KS has 300 different types of soil and prime farmlands form 25 million of the 52 million acres. Silt loam soil is the most extensive topsoil layer in $\mathrm{KS}$, and subsoil layer is grayish brown silty clay loam. The lower portion is calcareous silty loam, and the parent layer is a yellowish, calcareous silt loam with cretaceous sediments [30]. KS production is wheat, grain sorghum, sorghum silage. 
Some regions in NE are suited for cultivation while other regions are suited only for gazing and hay land. One of the big changes in $\mathrm{NE}$ is recovering the soil health from past anthropogenic practices that did not consider the climate change and soil conservation [30]. 385 soil types are classified in NE and most of them are formed under prairie grasses. The topsoil is Mollisols with dark color that is enriched with organic matter. The other soil is Entisols that lack distinct horizons because the high rate of erosion. These soils are in deposits on floodplains, sandy soils in the sand hills, and steep slopes [30]. Concentrations of the chemical elements in soil are small. However, the concentrations continue increasing and accumulating overtime that causes soil pollution, and can be geochemical anomalous [46]. Every geographic region has different features, which can determine the nature and the source of trace elements in that soil type. Comparison can be made of a control region (where there are exceptionally low agricultural activities). It is necessary to establish a background value for chemical elements in soils. The average concentration of uncontaminated soils for the chemicals of interest here are shown in Table $1[14,27,53]$. The average concentrations of the three elements were determined using the USGS data [53].

Table 1. Average concentrations of chemical elements in crust and soil (topsoil, A, and C. horizon). (a) [53], (b) [14], (c) world soil average [27].

\begin{tabular}{|c|c|c|c|c|c|}
\hline Element & Topsoil (a) & A-horizon (a) & C-horizon (a) & Soil 0-40 cm (b) & Topsoil (c) \\
\hline \multirow{4}{*}{ As } & \multirow{3}{*}{5.2} & \multirow{3}{*}{5.2} & \multirow{3}{*}{5.7} & IA 7.3 & \multirow{3}{*}{6.83} \\
\hline & & & & KS 6.8 & \\
\hline & & & & NE 5.5 & \\
\hline & \multirow{4}{*}{7.7} & \multirow{3}{*}{7.8} & \multirow{3}{*}{8.4} & IA 10.6 & \multirow{3}{*}{8} \\
\hline \multirow[t]{3}{*}{ Co } & & & & KS 8.8 & \\
\hline & & & & NE 5.3 & \\
\hline & & \multirow{3}{*}{0.02} & & IA 0.084 & \multirow{3}{*}{0.07} \\
\hline \multirow[t]{2}{*}{$\mathrm{Hg}$} & \multirow[t]{2}{*}{0.02} & & 0.02 & KS 0.058 & \\
\hline & & & & NE 0.039 & \\
\hline
\end{tabular}

\subsection{Physiography and Geology}

All three states are flat and varies exist associated with the river systems. The subtle topography makes the large-scale farms possible. Underlying deep soil and alluvium are nearly flat lying rocks of Peleozols and Mesozoic age. The greater part of IA is undergoing intense agricultural activity and high productivity. The eastern portion of KS and NE share this productivity. The western portion of $\mathrm{KS}$ and NE are much drier and do not have high agriculture productivity. Furthermore, north western NE contains the Sand Hills an immense region of Sands, with no agriculture, and which forms negative anomaly on maps.

\subsection{Soil Sampling and Chemical Analysis}

The data used in this study were extracted from United States Geological Survey (USGS) [52, 53]. Soil samples were collected from three horizons (surface soil $0-5 \mathrm{~cm}$, A-horizon, and C-horizon) and the result of chemical analyses reported. The C-horizon samples are collected from depth $18-167 \mathrm{~cm}$ in Iowa, depth $10-100 \mathrm{~cm}$ in Kansas, and depth $10-153 \mathrm{~cm}$ in Nebraska [52]. The topsoil and C-horizon data are used here. The samples sites in the three states are: 91 from IA, 132 from KS, 130 from NE.

\subsection{Data Analysis}

The typical method of analyzing geochemical data involves the description of the single element and spatial distribution. The statistical methods were produced using R Studio Version 0.98.1091. The topsoil data is plotted in histograms based on the concentration of elements and mean, and standard deviation. In this study, the chemical concentrations of the elements $\mathrm{As}, \mathrm{Co}$, and $\mathrm{Hg}$ in $\sim 353$ samples are used to conduct geostatistical analysis in IA, KS, and NE. The descriptive statistics graphs and histograms are produced (Figure 2a, 2b, and $2 \mathrm{c}$ ) and spatial distribution analysis is performed graphically (Figures 3, 4, 5) to display the distribution of the three indices. Geochemical distribution maps of EF, I geo, and PERI are performed using Geosoftware Oasis Montaj (version 7.5.1- 4, 2012). The spatial interpolation maps are obtained using ordinary kriging estimation. The spatial interpolation maps present the spatial distribution of the elements in surface soil based on geostatistical analysis. ToxMaps of the USEPA are superimposed with geochemical maps and are discussed in the last section of this article, to compare with elements hotspots.

\subsection{Indices: Enrichment Factor (EF) for Chemical Elements, Geo Accumulation (I Geo), and Potential Ecological Risk Indices (PERI)}

There are several indexes used to identify arithmetically the risk of potentially contaminated soils. Ecological risk assessment indexes provide inclusive tool for measuring the level of soil contamination; moreover, they show the variances in geographical features $[43,55]$. In this study, evaluation of the potential anthropogenic chemical loading intensity on the topsoil is investigated also by using more complex ratio includes EF [63], I geo [39], and PERI, [11]. Complications will be discussed below.

\subsubsection{Enrichment Factor (EF)}

$\mathrm{EF}$ is a significant indicator to distinguish the relative contributions between natural and anthropogenic chemical inputs into soils, and accumulation or depletion of the elements [10, 40, 43, 63]. EF evaluation is by connecting the abundance of target element in the examined soil (material source) normalized to the reference or standardized metal (Ti) 
in deep uncontaminated soil layer (C-layer) that originate in the Earth's crust or geological bedrock parent [42]. The content of chemical elements is measured with mass basis using the formula expressed as:

$$
\text { Enrichment Factor }(\mathrm{EF})=\frac{\left(C_{i} / C_{T i}\right) \text { surface sample }}{\left(C_{i} / C_{T i}\right) C-\text { horizon as background }}
$$

$\mathrm{EF}$ is a unitless measure as concentrations cancel out. Where $\mathrm{C}_{i}$ is the concentration of the target element and $\mathrm{C}_{T i}$ Is the concentration of $\mathrm{Ti}$ in the same sample. $\left(\mathrm{C}_{i} / \mathrm{C}_{T i}\right)_{\text {sample }}$ is the ratio of mean of the target element to Ti concentration $\left(\mathrm{C}_{T i}\right)$ in the soil sample, and $\left(\mathrm{C}_{i} / \mathrm{C}_{T i}\right)$ background is the ratio in the reference (conservative element) in C-horizon.

There are various methods to calculate EF. As an example, one method is calculating EF in element normalizer such as Fe or $\mathrm{Mn}$ concentration. Another method is using the ratio of the chemical concentration of a polluted site to a normalizer non-polluted site. Several references used different techniques to estimate EFs in the soil. Some of these used on-site references [10, 12, 32, 57], and others used off-site values or concentrations $[13,17,42,47,66]$. The chemical concentrations are normalized to conservative reference elements from the same site [12]. In off-site reference, using the mean of element content in the earth crust for normalization in EF calculations cannot provide the accurate background values. The elements in each regional natural background are different [5]. Values of the deep soil layer (C-horizon) are the most suitable on-site references of the same soil profile [10,12,45], and this is what it is used here.

The most common normalizers are categorized into two groups; the first group includes $\mathrm{Zr}$, Sc, and Ti. The second group includes $\mathrm{Al}, \mathrm{Mn}$, and $\mathrm{Fe}[9,42,43,50,57]$. $\mathrm{EF}$ of $\mathrm{Al}, \mathrm{As}$, $\mathrm{Cr}, \mathrm{Cu}, \mathrm{Fe}, \mathrm{Mn}, \mathrm{Ni}, \mathrm{Pb}$, and $\mathrm{Zn}$ were normalized using $\mathrm{Al}$ as a conservative element [34]. Mathematically, EF calculation using $\mathrm{Ti}$ as qualified, immobile, and standard element reference (normalizer) in the same sample site is accurate tool [49, 58]. Ti is not easily impacted by the weathering (conservative), which means it is abundant and originates from the Earth's crust [27, $35,58]$. Ti is used as the normalizer in this study because of many reasons: 1) It is an immobile element that has low existence availability; 2) It has little variability of mobility in the soil or particularly stable [12].

The three risk indices EF, I geo, and PERI each have their own numerical and verbal scales of relative intensity or risk, and they are not equal to each another. Table 1 shows the scales and comparisons. Five contamination categories are used, therefore, values of EF less than 1 indicate the likelihood of mobilization or depletion of metals respective to the reference, while increased EF values more than 1 suggest that the element level in the soil is anthropogenic in origin [43]. The classifications of the contamination indicators are described in Table 1 [7, 26, 40, 43, 59]. As EF values increase, the probable anthropogenic inputs increase [59] as it shown in Table 1.

\subsubsection{Geo Accumulation Index (I Geo)}

The accumulative index "I geo" is an environmental and geological assessment that is widely used to measure the magnitude of chemical elements loading relating with the studied sediments and soils since the 1970s. Many researchers applied "Igeo" index by [39] to assess different chemical elements contaminations such as $[3,4,21,23,24,36,43,63]$. To quantify the degree of chemical elements contamination, the mathematical equation proposed by Muller (1969) was calculated as follows:

$$
\text { I geo }=\log _{2} \frac{C_{n}}{1.5 B_{n}}
$$

$\mathrm{C}_{n}$ is the average concentration of metal " $n$ " in the soil (measured concentration of the examined metal), and $B_{n}$ is the background concentration of the metal (geochemical background concentration of given metal in the crust or reference value of the metal " $n$ "). The values of I geo index is determined by calculating the base 2 logarithm of the metal concentration of metal over its background concentration. I geo is a unitless measure as the concentrations cancel out.

The factor 1.5 is the background matrix correction factor for minimizing the impact of possible variations in the background values (it is used because of the possible variations in background values for a given metal in the environment as well as exceedingly small anthropogenic impacts) that may be attributed to lithologic variations or impacts in the soils [29]. Muller (1969) categorized I geo index into seven class indicators that are used to define the degree of metal contamination according to the criteria and these classifications are shown in Table 1.

\subsubsection{Potential Ecological Risk Index (PERI)}

Potential Ecological Risk Index (PERI) is a tool to estimate the degree of heavy metal loading in soils [65]. This method is used widely in a variety of environmental research domains to record pollutant inputs [54]. Hakanson (1980) [16] developed PERI using a toxic response factor for a specific metal to evaluate the combined pollution risk, because different types of metals can accumulate consecutively and cause combined pollution [54]. Each metal also has different effects. This technique determines the concentrations, ecological sensitivities, and toxic levels of chemical elements [25]. The equation of PERI is calculated as explained below:

$$
\text { PERI }=\sum_{i}^{\mathrm{n}}(\mathrm{TRF} \times \mathrm{CF})
$$

PERI does have a concentration unit $(\mathrm{mg} / \mathrm{kg})$. CF is the reported concentration, and TRF is toxic response factor that is the environmental response to the contaminant. TRF is known also as relative toxicity for chemical elements. Each chemical element has a different TRF value, which are $A s=10$, $\mathrm{Co}=5, \mathrm{Hg}=40, \mathrm{Ni}=6[11], \mathrm{Mn}=1[54,65], \mathrm{Cd}=30, \mathrm{Cr}=2, \mathrm{Cu}=5$, $\mathrm{Pb}=5$, and $\mathrm{Zn}=1[11,25,67]$. Once the calculation is made, the degree of ecological risk for each element can be determined according to PERI classification as it shown in Table 2 [11]. 
Table 2. Comparison of of numerically calculated values and word descriptions of three metrics, enrichment factor (EF), geo accumulation (Igeo), potential ecological risk index (PERI) classes (EF=Reference: [26], Igeo=[39], and PERI=[16].

\begin{tabular}{|c|c|c|c|c|c|c|c|c|}
\hline EF value & $\begin{array}{l}\text { EF } \\
\text { Class }\end{array}$ & $\begin{array}{l}\text { Designation of soil quality } \\
\text { (enrichment level) }\end{array}$ & $\begin{array}{l}\text { I geo } \\
\text { value }\end{array}$ & $\begin{array}{l}\text { I geo } \\
\text { Class }\end{array}$ & $\begin{array}{l}\text { Designation of soil quality } \\
\text { (Pollution Intensity) }\end{array}$ & PERI value & $\begin{array}{l}\text { PERI } \\
\text { class }\end{array}$ & $\begin{array}{l}\text { Designation of soil } \\
\text { quality (PERI) }\end{array}$ \\
\hline$<1$ & 0 & no enrichment & $\leq 0$ & 0 & Uncontaminated & $<40$ & 0 & low risk \\
\hline $1-2$ & 1 & $\begin{array}{l}\text { depletion or deficiency to } \\
\text { minimal enrichment }\end{array}$ & $0-1$ & 1 & $\begin{array}{l}\text { uncontaminated to moderately } \\
\text { contaminated }\end{array}$ & $\leq 40<80$ & 1 & moderate risk \\
\hline $2-5$ & 2 & moderate enrichment & $1-2$ & 2 & moderately contaminated & $80 \leq \mathrm{PERI}<160$ & 2 & considerable risk \\
\hline $5-20$ & 3 & significant enrichment & $2-3$ & 3 & $\begin{array}{l}\text { moderately to strongly } \\
\text { contaminated }\end{array}$ & $160 \leq$ PERI $<320$ & 3 & high risk \\
\hline $20-40$ & 4 & extremely high enrichment & $3-4$ & 4 & strongly contaminated & $\geq 320$ & 4 & extremely high risk \\
\hline$>40$ & 5 & Extremely high enrichment & $\begin{array}{l}4-5 \\
\geq 5\end{array}$ & $\begin{array}{l}5 \\
6\end{array}$ & $\begin{array}{l}\text { strongly to extremely } \\
\text { contaminated } \\
\text { extremely contaminated }\end{array}$ & & & \\
\hline
\end{tabular}

Calculated results of three environmental risk indices give unrelated numbers, indicated in value columns. These ranges of numbers are subdivided into classes of increasing environmental risk, by their authors. Designations of soil quality translates those numbers into words, but the words are arbitrary.

\subsubsection{Statistical Analysis}

The statistical analyses of the data are performed using SPSS 24 software. Descriptive statistics and ANOVA multivariate analysis using Tukey are used to estimate the variance between the means of the analyzed EF, I geo, and PERI. Duncan's Multiple Range Test (DMRT) is carried out to test the differences between means (significance level<0.05). The statistical analyses of the concentrations of elements are achieved by analysis of variance (ANOVA) followed by the Tukey's post-hoc test at the 5\% level (https://www.ibm.com).

\section{Results}

According to these datasets, some of the chemical levels have high concentrations, which could reflect possible soil contamination from anthropogenic activities. In most instances, regions overloaded with chemical elements in the soil are not associated with industrial applications, urban activities, and others. Furthermore, all these regions have been subjected to intensive agricultural activities. ToxMaps of the USEPA are superimposed with geochemical maps (Figure 6) and discussed in the last section as to whether anomalous regions are associated with the element hotspots.

The average of concentrations of $\mathrm{As}, \mathrm{Co}$, and $\mathrm{Hg}$ are shown in Table 3.

Table 3. Standard statistics of the chemical data (USGS) used in this study. Units are ppm. Maximum (Max), minimum (Min), standard deviation (SD).

\begin{tabular}{|c|c|c|c|c|c|c|c|c|c|}
\hline \multirow{2}{*}{ Chemical } & \multicolumn{3}{|l|}{ IA } & \multicolumn{3}{|l|}{ KS } & \multicolumn{3}{|l|}{ NE } \\
\hline & As & Co & Hg & As & Co & $\mathrm{Hg}$ & As & Co & $\mathrm{Hg}$ \\
\hline Max & 13.2 & 16.2 & 0.1 & 19.3 & 21.1 & 0.08 & 18 & 20 & 0.06 \\
\hline Min & 1.6 & 3.3 & 0.01 & 1.4 & 1.7 & 0.01 & 0.9 & 0.7 & 0.01 \\
\hline Average & 7.68 & 10.6 & 0.03 & 6.76 & 8.59 & 0.02 & 4.41 & 6.26 & 0.02 \\
\hline SD & 2.20 & 2.61 & 0.01 & 2.71 & 3.47 & 0.01 & 3.05 & 4.02 & 0.01 \\
\hline $\mathrm{N}=348$ & & & & & & & & & \\
\hline
\end{tabular}

Table 4. Enrichment Factor (EF), potential ecological risk index (PERI), and geo accumulation (Igeo) in Iowa (IA), Kansas (KS), and Nebraska (NE).

\begin{tabular}{|c|c|c|c|c|c|c|c|}
\hline EF & & \multirow{3}{*}{$\mathbf{N}$} & \multirow{3}{*}{ Mean } & & & I geo & \\
\hline Element & \multirow{2}{*}{ State } & & & \multirow{2}{*}{ Std. Deviation } & \multirow{2}{*}{ Degree of EF } & Element & \multirow{2}{*}{ Mean } \\
\hline Index & & & & & & Index & \\
\hline \multirow{4}{*}{ EF_As } & IA & 91 & 1.01 & 0.42 & minimal enrichment & \multirow{4}{*}{ Igeo_As } & 1.01 \\
\hline & KS & 127 & 0.9 & 0.31 & no enrichment & & 0.9 \\
\hline & NE & 130 & 1.01 & 0.51 & minimal enrichment & & 1 \\
\hline & Total & 348 & 0.97 & 0.44 & no enrichment & & 0.97 \\
\hline \multirow{3}{*}{ EF_Co } & KS & 127 & 0.9 & 0.2 & no enrichment & \multirow{3}{*}{ Igeo_Co } & 0.9 \\
\hline & NE & 130 & 1.03 & 0.28 & minimal enrichment & & 1.03 \\
\hline & Total & 348 & 0.98 & 0.25 & no enrichment & & 0.97 \\
\hline \multirow{4}{*}{ EF_Hg } & IA & 91 & 1.1 & 0.53 & minimal enrichment & \multirow{4}{*}{ Igeo_Hg } & 1.1 \\
\hline & KS & 127 & 1.4 & 0.81 & minimal enrichment & & 1.39 \\
\hline & NE & 130 & 1.12 & 0.54 & minimal enrichment & & 1.12 \\
\hline & Total & 348 & 1.21 & 0.67 & minimal enrichment & & 1.21 \\
\hline
\end{tabular}


Table 4. Continued.

\begin{tabular}{|c|c|c|c|c|c|}
\hline I geo & & PERI & & & \\
\hline \multirow{2}{*}{ Std. Deviation } & \multirow{2}{*}{ Degree of I geo } & Element & \multirow{2}{*}{ Mean } & \multirow{2}{*}{ Std. Deviation } & \multirow{2}{*}{ Degree of PERI } \\
\hline & & Index & & & \\
\hline 0.42 & uncontaminated to moderately contaminated & \multirow{4}{*}{ As_PERI } & 10.5 & 5.6 & low risk \\
\hline 0.31 & uncontaminated to moderately contaminated & & 9.8 & 4.04 & low risk \\
\hline 0.51 & uncontaminated to moderately contaminated & & 10.38 & 7.57 & low risk \\
\hline 0.43 & uncontaminated to moderately contaminated & & 10.2 & 5.96 & low risk \\
\hline 0.27 & uncontaminated to moderately contaminated & \multirow{4}{*}{ Co_PERI } & 5.22 & 2.07 & low risk \\
\hline 0.2 & uncontaminated to moderately contaminated & & 4.4 & 1.75 & low risk \\
\hline 0.28 & uncontaminated to moderately contaminated & & 5.34 & 3.28 & low risk \\
\hline 0.26 & uncontaminated to moderately contaminated & & 4.97 & 2.53 & low risk \\
\hline 0.53 & moderately contaminated & \multirow{4}{*}{ Hg_PERI } & 49.49 & 36.03 & moderate risk \\
\hline 0.81 & moderately contaminated & & 53.73 & 26.98 & moderate risk \\
\hline 0.54 & moderately contaminated & & 49.52 & 23.87 & moderate risk \\
\hline 0.66 & moderately contaminated & & 51.05 & 28.58 & moderate risk \\
\hline
\end{tabular}

Classification results of EF, PERI, and Igeo, and the values of the results to determine the contamination levels of As, Co, and $\mathrm{Hg}$ for each state are showed in Table 4.
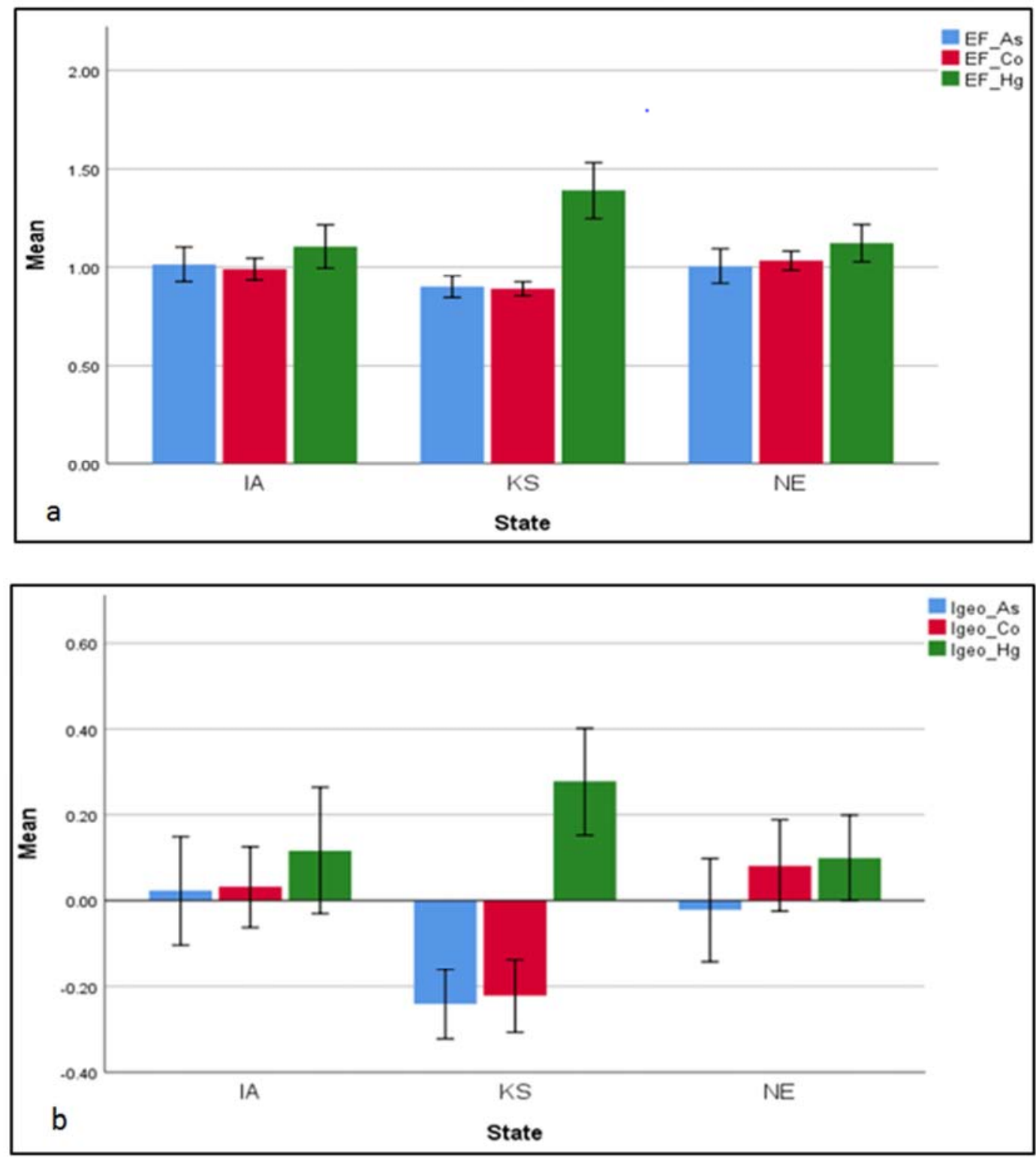


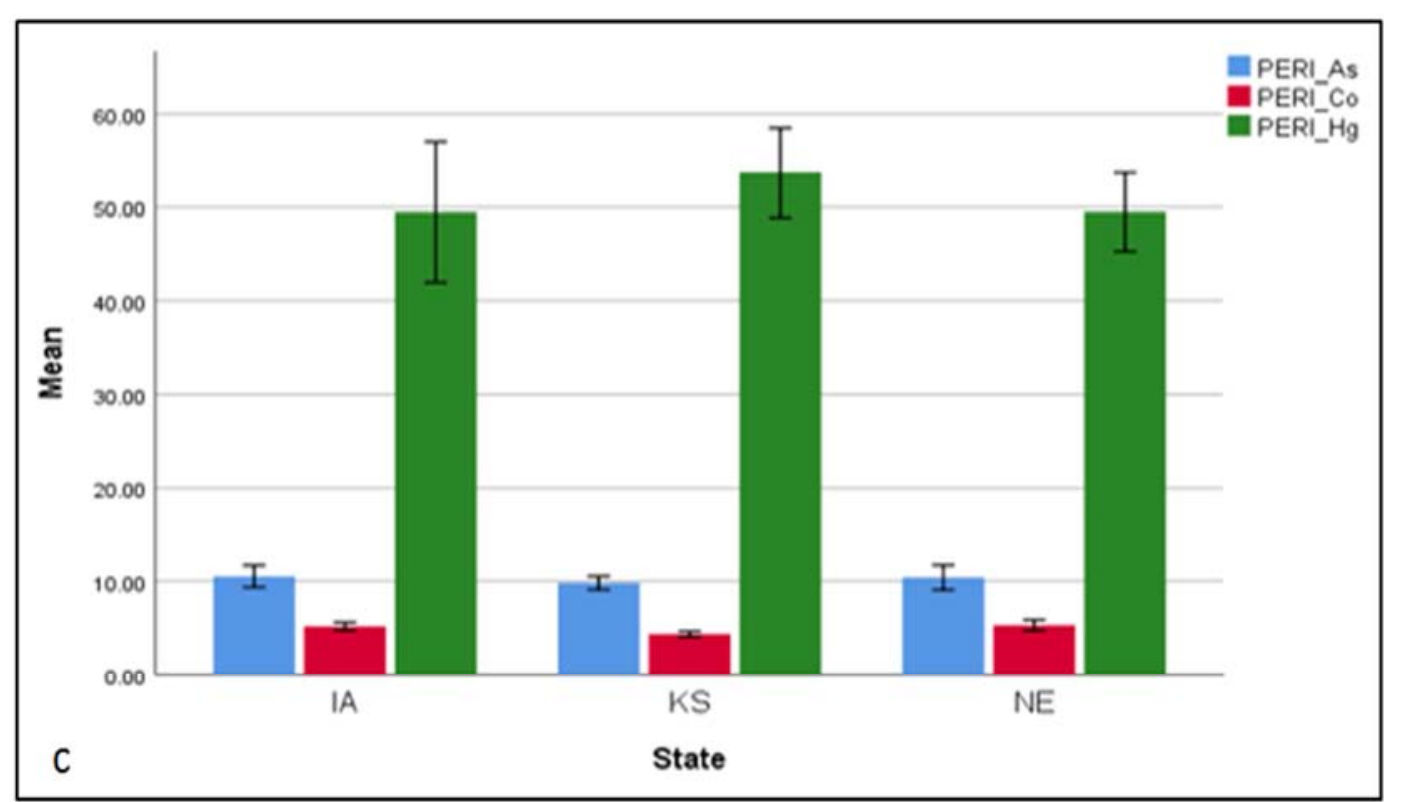

Figure 2. (a, b, c) Enrichment factor (EF), Geo-accumulation (I geo), Potential ecological risk index (PERI) values of individual chemical elements in surface soil in the study area.

\subsection{Enrichment Factor (EF)}

The enrichment of $\mathrm{As}$, Co, and $\mathrm{Hg}$ are evaluated by applying three frequently used methods. Table 4 shows the numerical values produced, the value range is subdivided, and each subdivision is given named description of soil quality, a qualitative name of degree of contamination. The summarized data for $\mathrm{As}, \mathrm{Co}$, and $\mathrm{Hg}$ displayed in different columns are shown in Table 2. Table 3 shows the statistical findings of three measurement tools used in this study. Figure $2 \mathrm{a}, 2 \mathrm{~b}$, and $2 c$ presents a graphical depiction of three different metric values on vertical axes by state on the $\mathrm{X}$ axis, and with each chemical assigned individually. Special classification of these data is displayed in Figures 2, 3, and 4, and will be discussed later.

The values of EF of chemical elements in the soils of the states vary because $\mathrm{Hg}$ and As have minimal enrichment and Co has almost no enrichment, which indicates that the soil in these states has minimal contamination by $\mathrm{As}$ and $\mathrm{Hg}$ as shown in Table 3. The enrichment degree of $\mathrm{Hg}$ is the highest. The highest value of EF of $\mathrm{Hg}$ is observed in $\mathrm{KS}$ (1.39) followed by NE (1.12) and IA (1.10). However, enrichment degree of As is lower than $\mathrm{Hg}$ and higher than Co with the values $1.01,0.90,1.00$ in IA, KS, and NE respectively. Enrichment intensity of $\mathrm{Co}$ is lowest compered to As and $\mathrm{Hg}$ and its average in IA (0.99), KS (0.89), and NE (1.03) (Table 3 $\&$ Figure 2a). In general, the values of EF are approximately similar or close to each other for the three elements in the three states. The maps of EF are shown in Figure 3.

\subsection{Geoaccumulation (I Geo)}

Results of Igeo calculation shown in Table 3 investigate whether that the three states are contaminated with $\mathrm{Hg}$ (Table 3 \& Figure 2b). In general, the values of I geo are approximately similar for $\mathrm{As}, \mathrm{Co}$, and $\mathrm{Hg}$ in the three states, but the chemical element with the highest index is $\mathrm{Hg}$ with maximum value 1.38 in $\mathrm{KS}$, followed by 1.12 in NE, and 1.10 in IA (Table $3 \&$ Figure $2 b$ ), which shows the possibility of the contamination in the soil with the $\mathrm{Hg}$ originating from human activities (Table 3 ). The highest maximum values of I geo observed in KS are As (1.90) and $\mathrm{Hg}$ (1.38).

\subsection{Potential Ecological Risk Index (PERI)}

PERI is a simple and accurate method that can be used for estimating the environmental aspects of chemical elements in the soil. There is a significant ecological risk contamination of $\mathrm{Hg}$ in the soils of IA, KS, and NE. According to the evaluating standard of PERI, $\mathrm{Hg}$ is classified as a moderate risk in IA (49.5), in KS (53.7), in NE (49.5). As and Co are evaluated as low risk assessment according to PERI criteria (Table 3 \& Figure 2c). These investigations show that these chemical elements are associated with point sources and various additional sources (Figure 6).

Histograms and standard statistic parameters lead towards a better understanding of data. Multivariate statistical analysis illustrates the geochemical groupings inherent in the samples.

\subsection{Spatial Distribution Maps of Chemical Elements Using Enrichment Factor (EF), Geo Accumulation (I Geo), Potential Ecological Risk Index (PERI)}

Spatial analysis is initially different. Description when necessary, initially mimics is the description of an anomaly map. Description may be carried out in a fashion like a geomorphology map, describing hills, valleys, etc. From this perspective, the following terms are defined for the generalized description of this special variable. In geology, these interests are called geomorphology. Background equal zero, it is important for there to be an area where zero or close 
to zero chemical concentrations are present. This is the case in the Sand Dunes in northwest Nebraska. This large region of wind-blown sand of largely quartz and is not and never has been under cultivation. It serves as a region of near zero values for all chemical constituents. Regional plateaus are areas of broad non-zero, relatively uniform anomalies, will be interpreted to be of agricultural origin, from fertilizers and additives. Ridges and basins are linear anomalous features of positive (ridges) or negative (basins) values. Grabens and horsts are alternative parallel valleys and uplifts. Moreover, embayments are entries into a regional plateau or other feature, which may merge with the other features. Dimples are site specific, circular anomalies; on a fertilizer derived regional plateau dimples may be towns, within which fertilizer nor additives are not applied (negative anomaly). Otherwise, dimples as positive anomalies are point sources due to industrial activity and may be seen ToxMap (Figure 6). Boundaries may consist of large value changes over short distances, as measured in general perpendicular to the trend of the boundary. Alternatively, perpendicular to the trend of the shape the rate of change of the measurement is relatively slow.

This section is concerned with maps. The point sources of local distributed maps are produced to show the single element geochemical distribution (Figure 6). These techniques are valuable indicators for identifying the actual sources of chemicals. The maps of the soil provide a baseline data regarding to distribution and accumulation of the elements as projected by kriging and mapped in Figure 3, 4, and 5. Spatial variation patterns of EF show differences from site to site. interpretation of the spatial data shows the relationship among the chemical element concentrations and potential soil contamination. EF index is translated and displayed in distribution maps of these three chemicals $\mathrm{As}, \mathrm{Co}$, and $\mathrm{Hg}$ in Figure 3. The map patterns display different features. Some of these zones with high metric values may be related to potential agricultural, anthropogenic applications. These regions have been put in risk because of historically intensive agricultural inputs.

Most of the individual EF values are between 2-5 indicate to moderately enrichment. The maximum values in the spatial chemical distribution of EF maps show the differences between elemental concentrations. The EF maps of As show the range of values between 0.5-2.6. The maximum value of 2.6 suggests moderate enrichment as it is described in Table 2 [26] in some regions especially in the east of IA, north west, middle, south of NE, and north, southwest of KS (Figure 3a). However, the minimum value of EF is 0.5 observed in some areas in IA, KS, and NE (Figure 3a). The spatial pattern of EFs values of $\mathrm{Co}$ in agricultural soil falls within range 0.5-2.1 (Figure $3 b$ ). The Co hotspots of EF are identified in southern IA and northern NE. In KS region, few moderate EF areas have been observed (Figure $3 \mathrm{~b}$ ). Greater $\mathrm{EF}$ of $\mathrm{Hg}$ is 7.6, indicating significant hotspot enrichment observed through many regions in $\mathrm{KS}$, especially in the east side. In IA, EF of $\mathrm{Hg}$ in elevated in northeast and southeast, and one hotspot is in the south of the state (Figure $3 \mathrm{c}$ ).

The soil elemental content varies in geochemical distribution in different sites as it is evaluated by the I geo calculation. The results of the mapping analysis of point sources showed different patterns. The soil in the study regions is potentially affected by different sources of anthropogenic applications. The distribution of geochemical maps of I geo for the analyzed chemical elements indicate high spots in specific regions compare to other regions within each state. The minimum negative values were observed in some regions in the study area. High concentrations of hotspots have been observed in IA, KS, and NE. According to I geo, agricultural soils in IA, KS, and NE are chemically loaded with $\mathrm{Hg}$ (1.63) as shown in I geo distributed maps (Figure 4c). It is noted that similar geochemical distribution maps are observed of I geo of As and Co. The maximum value of I geo of As is 0.52 while it is 0.31 of Co (Figure $4 \mathrm{a}$ and Figure $4 \mathrm{~b})$. The I geo values range of $0-1$ refers to uncontaminated to moderately contaminated soil [39] (Figure 4a, 4b, 4c).

Visual variations are observed in the maps with high and low values of the elements (Figure 5a, 5b, and 5c). The unique spatial distribution is observed at the local scale characterized by the location of hotspots. There are regions of high concentrations of $\mathrm{As}, \mathrm{Co}$, and $\mathrm{Hg}$ in the three states that are not associated with air and land emissions of Toxmap (Figure 6). Specifically, the highest concentrations of As range 21-59 $\mathrm{mg} / \mathrm{kg}$ is observed in the east of IA, the middle of NE, and the south of KS. Some of the elemental features among them display their dispersion by human inputs. However, the concentrations of Co range $10.74-27.86 \mathrm{mg} / \mathrm{kg}$ and $\mathrm{Hg}$ range $111.10-280 \mathrm{mg} / \mathrm{kg}$ are relatively low compared to As (Figure $4 \mathrm{~b}$ and $4 \mathrm{c})$.

A massive anomaly or plateau of As is noted in western IA and southern $\mathrm{KS}$, and the plateau is largest in the northwest and it extends to the middle of NE. These highlighted regions are interpreted to be associated with the anthropogenic activities. For Co, there are two massive diffuse anomalies in Sand Dunes in northwest NE. Moreover, a small anomaly region exists in the east of the state (Figure $5 \mathrm{~b}$ ). Very minor anomalous region is in the south of $\mathrm{KS}$ (Figure 5b). Furthermore, negatively minor anomalies are present in different places in IA. A region of low values exists in the south, east, and northwest of KS (Figure 5b). The significant point that should be taken in mind is the high values of PERI (21 - 59.44) of As in several random regions suggest mostly overloaded chemical inputs from different anthropogenic sources in the study area (Figure 5a). Though low PERI values of $\mathrm{Hg}$ are higher than As and Co investigated, the areas of anomalies are small to be visible in the spatial distribution of the maps.

Most of the regions in IA, KS, and NE in the land maps are agricultural regions rather than industrial regions, therefore the origin of some chemical elements might be sourced from anthropogenic activities and more specifically overloading of chemo agricultural substances. According to these results, the existence of significant soil contamination due to agricultural metal loading has taken place in the study areas. This explains the variations in distribution of the chemical elements with 
high and low concentrations in the spatial distribution maps.
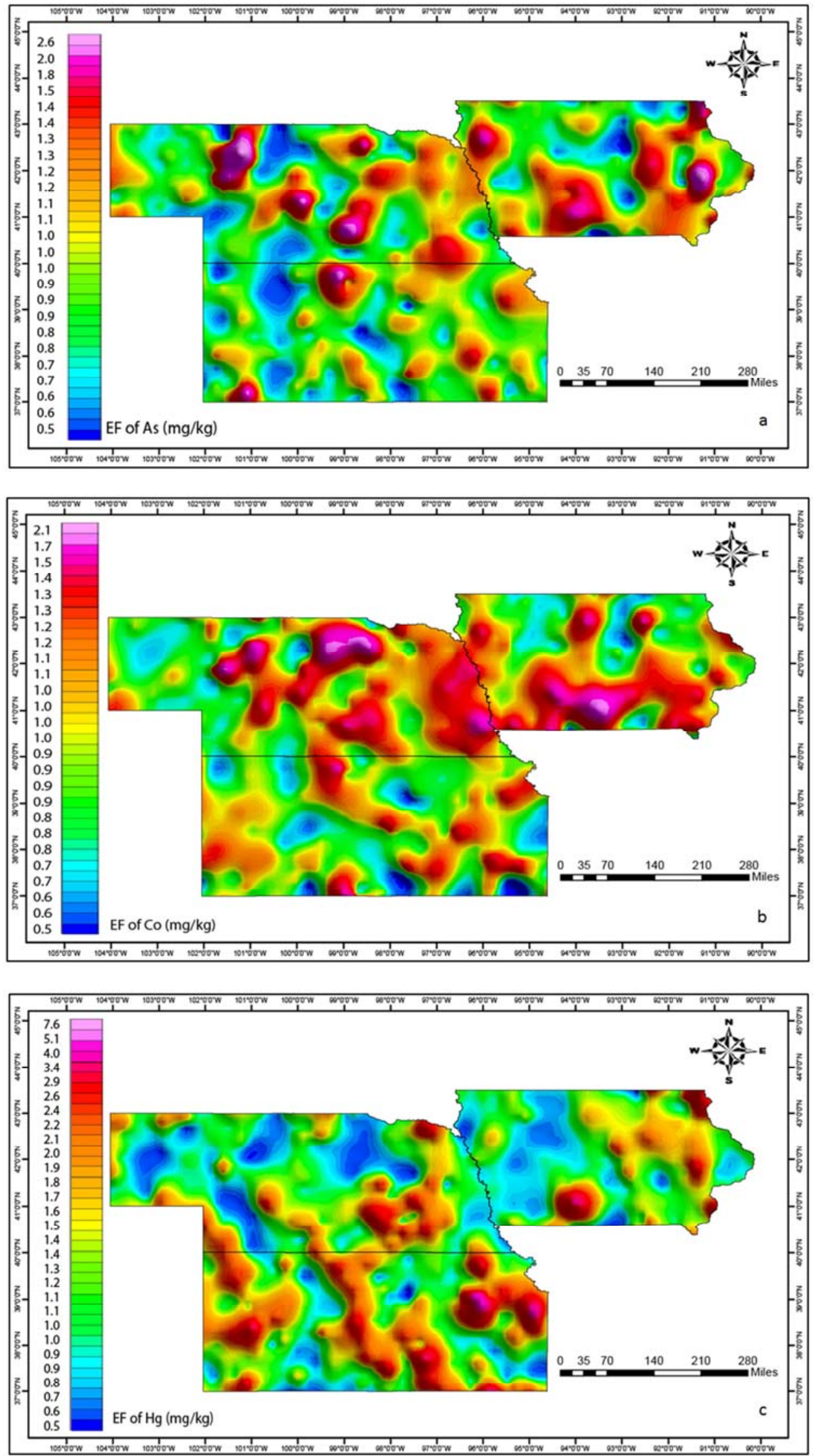

Figure 3. Spatial distribution maps show EF value of (a) As, (b) Co, (c) PERI in the surface soil in study area. 

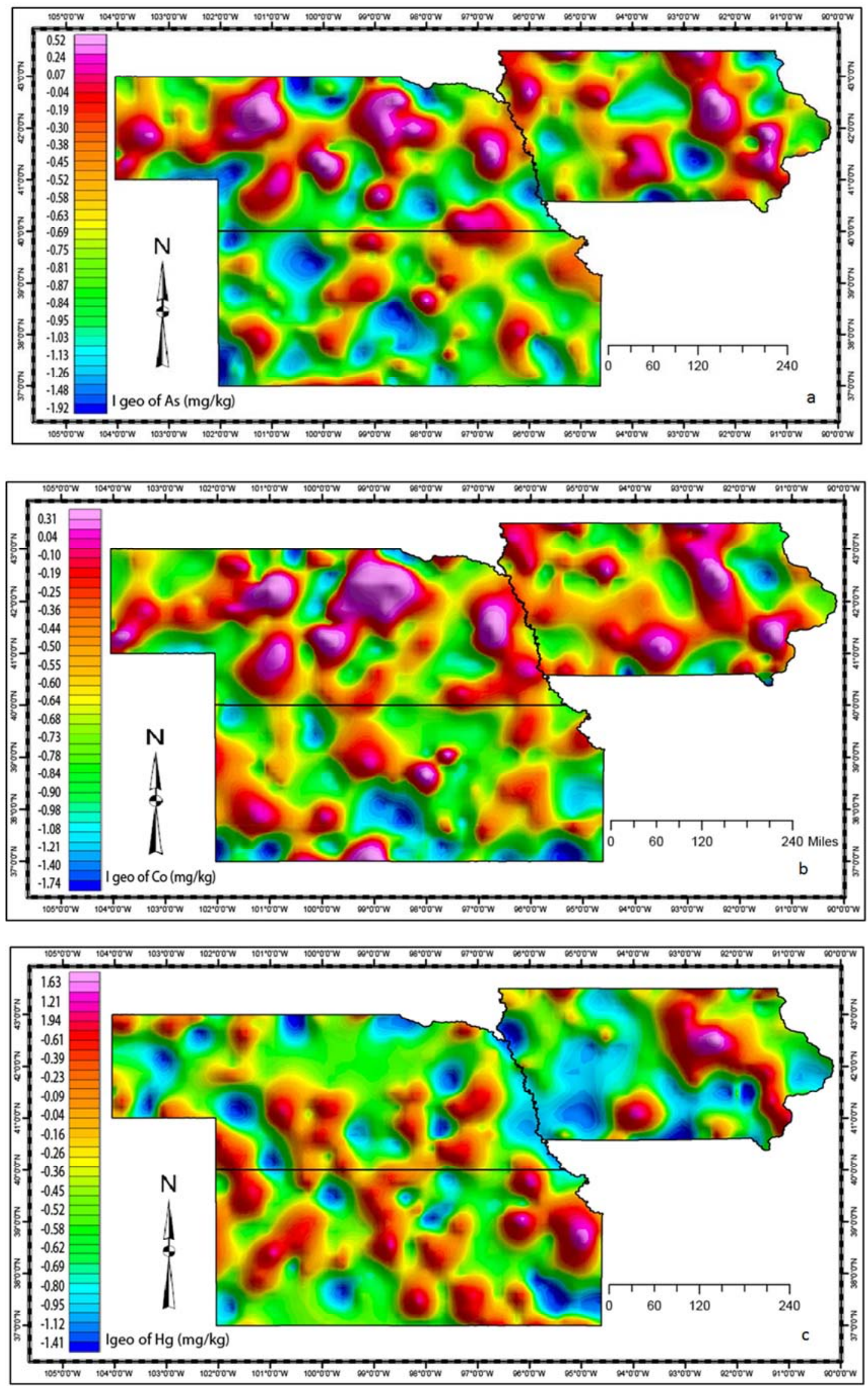

Figure 4. Spatial distribution maps show I geo value of (a) As, (b) Co, (c) $\mathrm{Hg}$ in the surface soil in study area. 

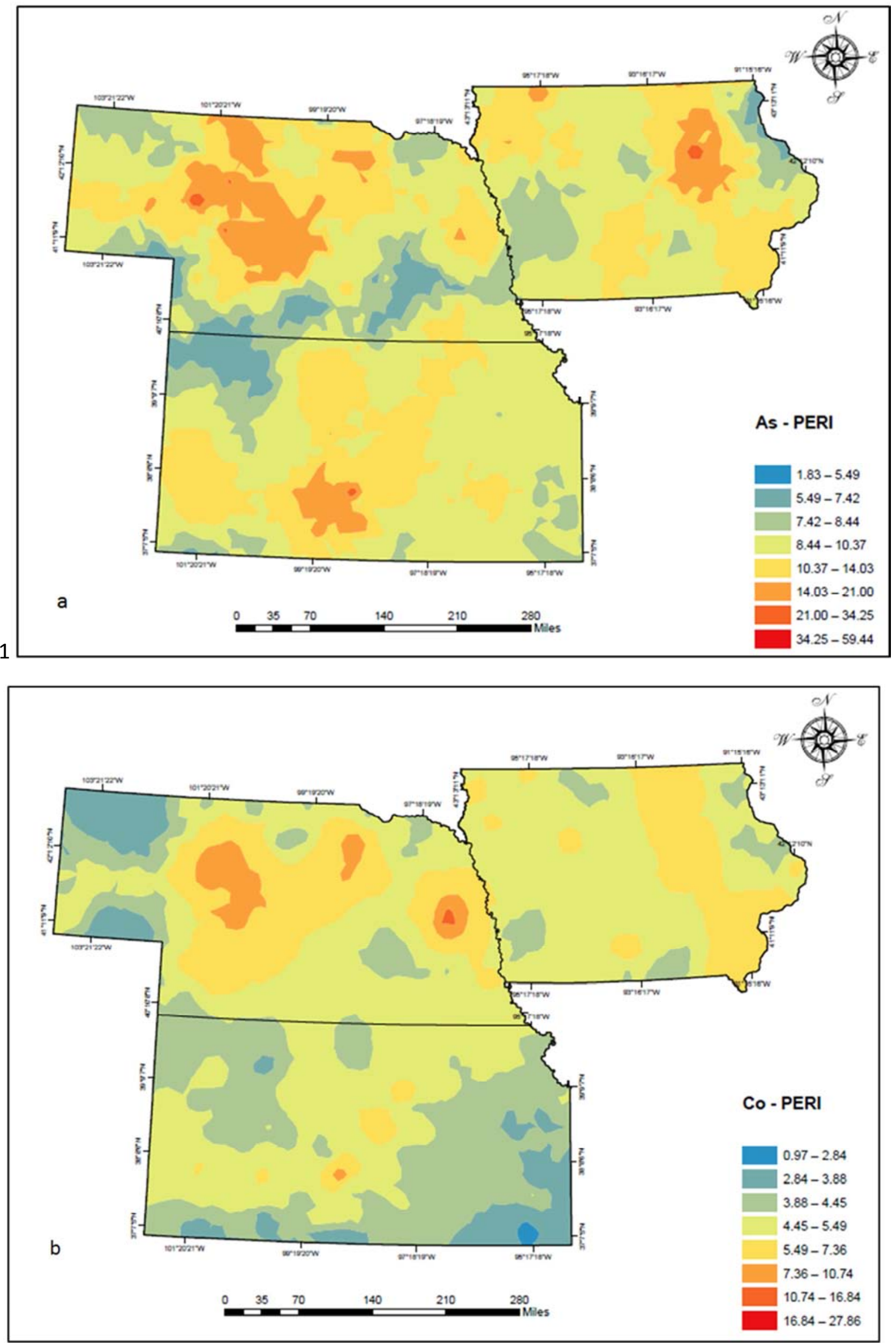


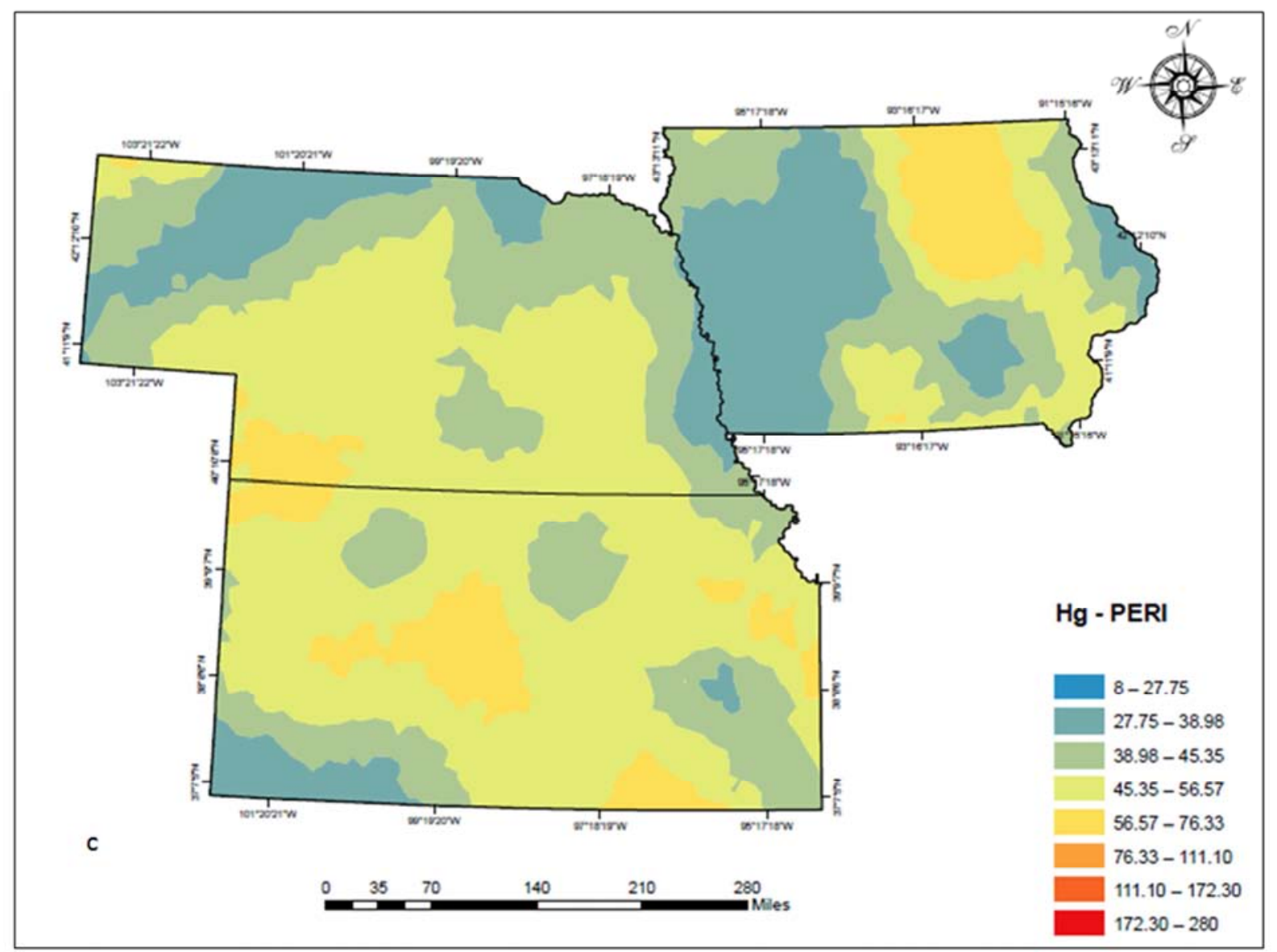

Figure 5. Spatial distribution maps show PERI value of (a) As, (b) Co, (c) Hg in the surface soil in study area.

\section{Toxmap Data of Individual Chemical Elements}

For further source identification and assessment of the chemical elements in the soil, the database of chemical elements released into the environment are extracted from the toxic release inventory (TRI) including the toxic chemical release information and the waste management activities [6]. ToxMap is a Geographic Information System (GIS) database and provides data on point airborne sources and surface industry sources. ToxMap maps to help users explore data from the USEPA, Toxics Release Inventory (TRI), National pollutant release inventory (NPRI), and superfund programs with visual projection and maps [62]. They help researchers to generate regional information that show the TRI chemicals released on site into different environments (air, land, water, and by underground injection). The released data are measured in pounds per year. These data facilitate identification and color-coded release quantities and chemical release data for many years. ToxMap hot spots are compared with the anomalous areas of maps produced here of surface soil chemistry and metrics to explore alternative sources of chemicals. Since the toxic chemicals released are reported for industrial activities, the other possible sources such as transportation, farming, and households are not involved [62]. Chemical sources may be from many possible human activities or natural processes. For this reason, the geochemical metric maps are compared with the Toxmap distribution maps of air emission [61]. The geochemical maps using USGS data of the surface soil metric have been created for overlapping these maps with ToxMap as it shown in Figure $6 \mathrm{a}, 6 \mathrm{~b}$, and $6 \mathrm{c}$.

In conclusion, there are no significant contributions and associations between air pollution data (Toxmap) and the observation of EF, I geo, and PERI documented in this study. It is critical to consider many factors to discover the source of the chemical anomalies. One factor is the number of high emissions and the anomalies spots. Another factor is that the number of the sites differs for each chemical. It is stated that the chemical sources are different from one site to another because the industrial activities in each site differ in chemistry such as in eastern KS. Generally, in all the maps, it is considered that the anomalies revealed that most of the ToxMap results are close to zero (Figure 6). The number of As releases to air and land are exceptionally low as it shown in the air release map of As, and there are no reported sites of As release into the air in the three states. However, for As release into the land, there are only two reported sites, one of these sites is in the border between IA and NE, and another is a waste center located in the southwest of NE. These sites do not correlate with any of high values indicated in the maps produced here (Figure 6a).

The soil anomalies are not associated with the Co released 
in the study area into the air (Figure 6b). Generally, there are no releases of Co onto the land that been observed in IA, NE, and KS (Figure 6b). These observations suggest that the source of $\mathrm{Co}$ in the soil is anthropogenic. Only one point source of $\mathrm{Hg}$ released from air and another point of land emission in the south of IA are correlated with hotspots in geochemical map of $\mathrm{Hg}$ in this study. In contrast, there are no correlation between air and land emissions and hotspots of $\mathrm{Hg}$ in geochemical maps of KS and NE (Figure 6c).

Point source maps of the three chemicals are given in Figure $6 \mathrm{a}, 6 \mathrm{~b}$, and $6 \mathrm{c}$ have little to zero influence on the maps generated here. The most important features in the present work are regional plateaus. These plateaus can be interpreted as agricultural additions to the soil because of the widespread elevated uniform properties.
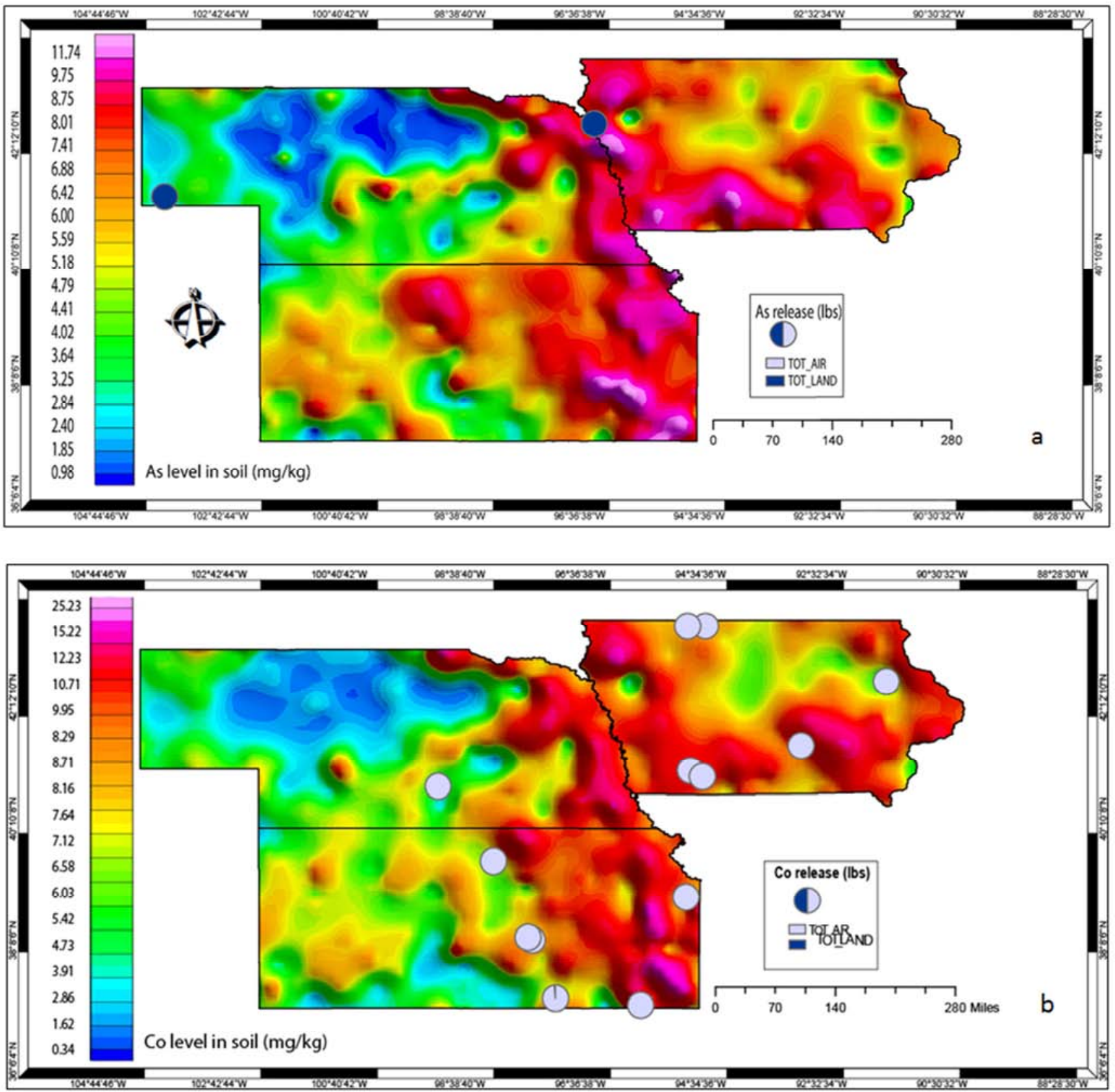


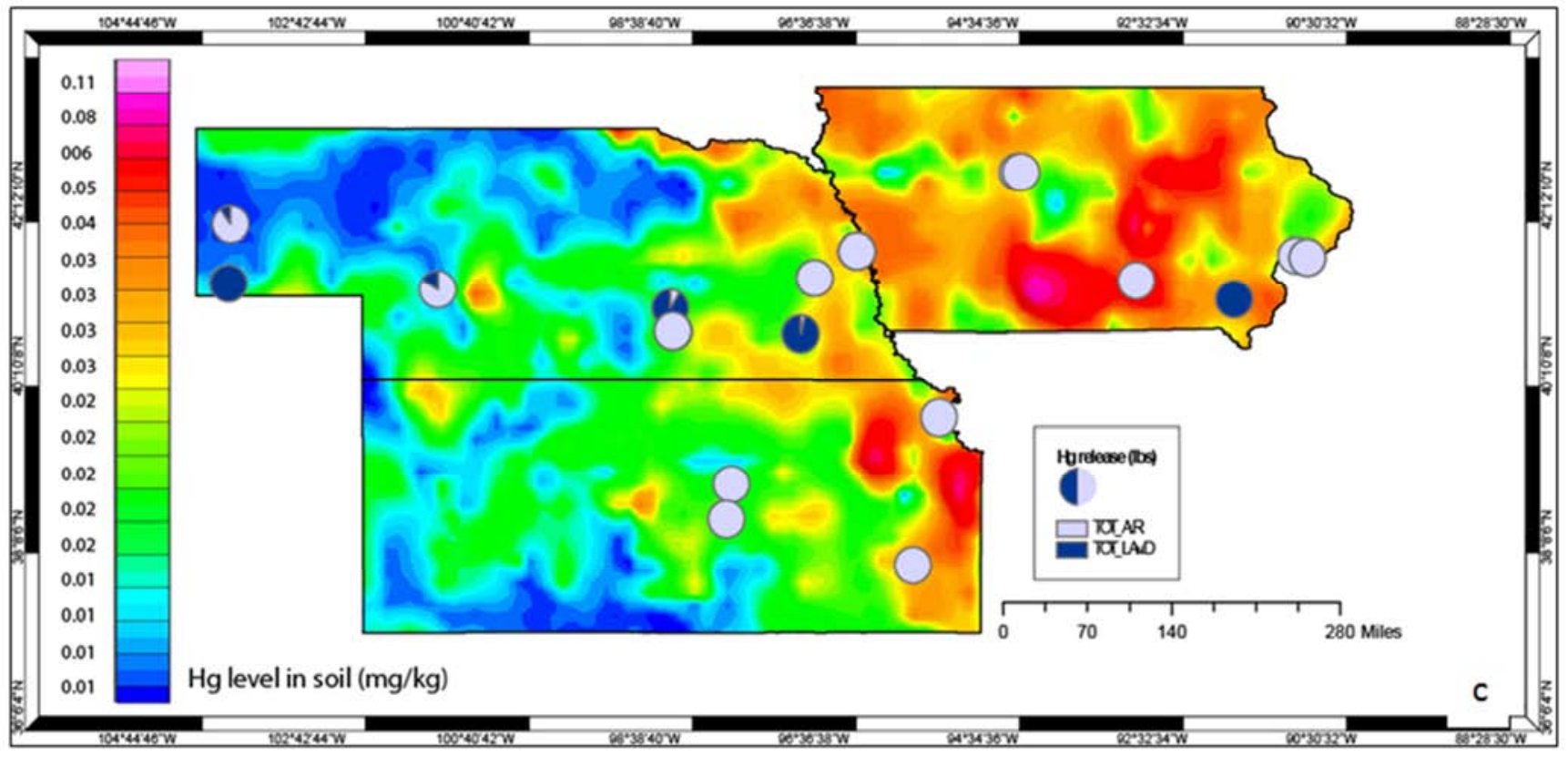

Figure 6. Maps of air and land emissions super imposed on soil geochemical background maps of (a) As, (b) Co, and (c) Hg.

\section{Discussion}

Soils of the USA have properties that result from the climate and geology. Investigations began with the three states of IA, KS, and NE. There is also a useful path of eye motion in investigating multiple maps of the same region, start with the Sand Hills a zero region, and moves south across $\mathrm{KS}$, and then turning eastward, and subsequently northward. The specific area of study was examined because it has a unique geological characteristic, and it is a relatively flat region. Geologically, it is underlain by relatively flat lying sedimentary strata consisting of limestone, sandstone, and shale, rocks which have simple chemistry and are impoverished in trace elements. The only exception to this statement is black shale, which may contain trace elements concentrations of $\mathrm{Hg}, \mathrm{Se}$, As, and others. Black shale constitutes less than $2 \%$ of the bedrock of these three states and is present in only limited areas, thus could not explain the wide, extensive, plateau like anomalies seen on the maps.

Another soil type is loess, which is windblown post glacial dust. The chemistry and locations of loess deposits have been studied in detail $[15,38,56]$ they are commonly in long linear bodies adjacent to water sources. Loess soils do not have any relationship with geochemical anomalies reported here. Another geological influence on soils was the recent $(10,000$ years ago) glaciation. Multiple times vast, continent sized glaciers moved south pushing loose surface material at its front. The region of IA is one of the exceptional agriculturally productive regions of the world and it exports the agricultural products over the world. Chemical fertilizers are used to economically optimize agricultural productivity [51].

The rocks are not enriched with these elements. Thus, these elements are potential agricultural derivatives. The geochemically anomalous regions reflect the anthropogenic applications. In the states considered here, the geology is relatively simple and the rocks are not enriched anomalously chemically, except for rare black shale. The concentration of $\mathrm{As}, \mathrm{Co}$, and $\mathrm{Hg}$ in argillaceous sediments and shales are 13, 20 , and 0.4 respectively [2].

Element concentration in the present study was different from other studies conducted in various areas in other countries. For instance, the mean concentration of Co investigated in this study were $10.6,8.59$, and $6.26 \mathrm{mg} / \mathrm{kg}$ in IA, KS, and NE respectively, which were lower than the reported mean concentration in ppm (506.02) by Odat, 2015 [44]. Compared to $\mathrm{EF}$ of Co in IA, KS, an NE $(0.10,0.90,1.03)$ respectively, it was lower than EF of Co (5.33) demonstrated by Odat, 2015 [44]. As values in the current study showed in Table 3 had lower concentrations compared with the investigated levels in soils in paddy fields of Fujian province in China presented a mean value of 22.60 [28]. However, Co mean values were the same in the current study in IA as reported by [28], but lower than estimated in KS and NE (Table 3).

The mean concentrations of As in the soil depth of $0-25 \mathrm{~cm}$ and $25-50 \mathrm{~cm}$ were $7.93 \pm 2.65$ and $7.89 \pm 2.29$ respectively, which were close to the mean values investigated in this study while mean concentrations of $\mathrm{Hg}$ in the same depth were $0.14 \pm 0.16$ and $0.09 \pm 0.09$, which were higher than mean values demonstrated in this study. The mean concentrations of As (16.17) and Co (13.15) in the urban area, which are enriched compared to the investigated values in the current study [36]. The concentrations of chemical elements in the soils may have been elevated because of the anthropogenic inputs such as industrial activities and fertilizers applications, and others. Many studies have applied EF to evaluate enrichment of the chemical elements in soils [10, 40, 43, 63]. Co was enriched significantly in the soil of the industrial A2 (11.21), while A7, and A8 zones with EF 5.16 and 2.15 respectively were moderately enriched, while the other zones were depleted to mineral enriched with values less than 2 . 
Meanwhile, I geo of Co in all zones was less than 1 indicate to unpolluted soils [22]. The mean concentration of As in agricultural soils around the industrial region of Tan-Gail district, Bangladesh was $5.90 \mathrm{mg} / \mathrm{kg}$, which is lower than reported values in the current study in IA (7.68) and KS (6.76) and higher than the estimated value in NE (4.41). Szolnoki et al., 2013 [57] reported EF of As (0.90) and Co (0.95) that were close to the EF values of As demonstrated in this study in IA (1.01), KS (0.90), and NE (1.01), and the EF of Co in IA (0.10), KS (0.90), and NE (1.03). The levels of As in this study were lower than its level in the west coast of Peninsular Malaysia. However, Co concentration was higher in the present study compared to Looi et al., 2018 [33].

Comparison of the A horizon can be informative. If the concentration in $\mathrm{A}$ is greater than $\mathrm{C}$, it is suggested is of an anthropogenic origin. It is stated that the air pollution with chemical elements that can be transported into topsoil, which dependent on the chemical and physical properties of the soil, indicates the variation of I geo in the different regions [31]. The mean I geo of Co reported in the current study in IA, KS, and NE $(0.91,1.03$, and 0.97$)$ respectively, which was higher than I geo of Co investigated below 0 by Odat, 2015 [44].

In the present study, the I geo concentration of As was in IA (1.01), KS (0.90), and NE (1), and Co was in IA (0.91), KS (0.90), and NE (1.03), which classified as uncontaminated to moderately contaminated, and these values were higher than the reported values 0.24 and $0.21 \mathrm{mg} / \mathrm{kg}$ by Adeyeye et al., 2018 [1]. The mean concentration of I geo of As the present study were in IA (0.42), KS (0.31), and NE (0.51), which were lower (1.27) than documented by Kang et al., 2020 [29]. However, I geo of Co was in IA (0.91, KS (1.03), and NE (0.97), which were higher than the value presented by Kang et al., 2020 [29].

According to the mean PERI, As for the present study is classified as low risk in IA (1.50), KS (9.80, and NE (10.38). Conversely, PERI of As showed moderate risk to very high risk ranged from 8.20-148.85 in different sites of agricultural soils around the industrial areas in Bangladesh [48]. The concentrations of PERI of As in the surface soil in the current study were in IA (10.50), KS (9.80), and NE (10.38) that were higher than the PERI of As investigated by Kang et al., 2020 [29]. Meanwhile, PERI of Co was in IA (5.22), KS (4.40, and NE (5.34), which is lower than investigated by Kang et al., 2020 [29].

Selection of these three states was done to simplify variables. Topographic relief is low. Rainfall increases from west to east. Temperature increases from north to south. Three rock types, limestone, sandstone, and shale essentially make up the entire bedrock of the three states. These sedimentary rocks are horizontal in the earth, or in large swells called anticlines or synclines. Soils are thick and productive. This area is part of the agricultural heartland of the US, the breadbasket of the US. These activities decrease in western KS and NE. Much was learned in the three-state focus, partly, how to deal with the resulting-colored maps. Geomorphology describes features on the surface of the earth, and this is a good comparative method. Plateaus become particularly pertinent.
Drainage from these states is down the Missouri and Mississippi River, and presently, in the Gulf of Mexico at the mouth of the Mississippi, there is a large plume of excess nutrients and trace elements producing a dead zone in the ocean caused by excessive fertilizer application in that river drainage [18].

Comparison of previously proposed environmental risk measuring parameters has been accomplished. Three elements present in this paper include As, Co, and $\mathrm{Hg}$. These elements were studied because they have high toxicity, bioavailability, and have influence on the economic and agricultural sectors [51]. Moreover, the application of agrochemical fertilizers into the soils has been widely used for a long time. Another reason is that the contamination of water with these elements is a critical and widespread problem. Geochemical maps of USGS data permit the expansion of ideas generated in the tristate region and leads to some entirely new observations. The largest Sand Dunes in North America are the Sand Hills in northwest NE. Specifically, one of the most distinctive features on the geochemical maps are the Sand Hills located in the northwest of NE which appears as a blank or ground zero in all the geochemical maps. It is all quartz sand, and the overwhelming predominance of quartz sand has precluded agricultural activities, and nothing lives in this large area. For regional geochemical studies, the Sand Hills serves as an excellent zero point, where the concentrations of most chemical elements go towards zero.

A large almost square plateau exists repeatedly in the geochemical data. A generalization of those boundaries is made and presented in Figure 3, Figure 4 and Figure 6. The square plateau boundaries are not parallel to the straight state boundaries but inclined approximately 45 degrees. The boundaries so the square BB Plateau join the following points: The Plateau includes most of eastern KS. From the southeastern corner of KS, a zone extends northeast to the IA state boundary, and therefore is the southeast boundary of the square, the BB Plateau. The northeast boundary of the square plateau extends northwest across western IA to the southeast corner of South Dakota, the northernmost corner of the square. The northwest boundary of the square runs from the southeast corner of South Dakota to a point west along the KS-NE boundary. A plateau exists for many chemicals, meaning that throughout this plateau area the concentrations of multiple chemicals are elevated slight variation of concentrations within the Plateau is the typical behavior. Two of the states in the tristate area of interest here are in a west to east sequence along which agricultural intensity increases, NE to IA. This is the western end of an unusual zone of agricultural productivity.

\section{Conclusion}

The environmental indices include EF, I geo, and PERI used in this study show similar results for each of the three chemical elements As, Co, and $\mathrm{Hg}$. The results demonstrate minimal contamination to moderately contamination in the study regions. EF shows present minimal enriched or low risk 
of chemical elements As and Co while I geo show uncontaminated to moderately contaminated As and Co. The mean value of $\mathrm{Hg}$ using $\mathrm{EF}$ as a contamination index indicate minimal enriched soils; PERI and I geo show moderate contamination in three states.

The spatial distribution maps show by EF, PERI, and I geo with several variations and high anomalies in three states with highlighted regions of plateaus are concluded to be related potentially with anthropogenic applications. High concentrations of $\mathrm{As}, \mathrm{Co}$, and $\mathrm{Hg}$ have been observed in the study area that could be associated with the human inputs. Like EF and PERI maps, the geochemical distribution maps of As, Co, and $\mathrm{Hg}$ using I geo present hot spots in some regions in the three states, which can indicate significant anthropogenic applications and point sources contamination in the study regions.

Spatial distribution of the chemicals and their risk metrics show widespread, uniform, elevated character, like a plateau. Agricultural applications can be the only explanation of origin of these geochemical features. Further study is needed to be understanding the sources and extent of accumulation of chemical elements in agricultural soils and assessment of study health risk in mid-continent of USA to reduce metal loading and avoid long term accumulation of chemical elements.

\section{Acknowledgements}

This study was a part of a $\mathrm{PhD}$ dissertation of the first author. The authors would like to thank the Department of Geological Sciences and the Environmental Science and Engineering Program at University of Texas at El Paso and for supporting this research and it is significantly appreciated.

\section{References}

[1] Adeyeye, E. I., Shittu, O. S., Ayodele, O. J., Ilori, A. O. A. (2018). Heavy metal pollution potential in soil influenced by sawmill operations at Ado-ekiti, Nigeria. Bangladesh J. Sci. Ind. Res. 53 (1), 29-34.

[2] Adriano, D. (1992). Biogeochemistry of Trace Metals. Lewis Publishers. p. 63.

[3] Aiman, U., Mahmood, A., Waheed, S., Malik, R. N. (2016). Enrichment, geo-accumulation, and risk surveillance of toxic metals for different environmental compartments from Mehmood Booti dumping site, Lahore city, Pakistan. Chemosphere. 144: 2229-2237.

[4] Amadi, A. N., Nwankwoala, H. O. (2013). Evaluation of heavy metal in soils from Enyimba Dumpsite in Aba, southeastern Nigeria using contamination factor and geo-accumulation index. Energy Environ. Sc. 3 (1), 125-134.

[5] Anderson, R. H., Kravitz, M. J (2009). Evaluation of geochemical associations as a screening tool for identifying anthropogenic trace metal contamination. Environ Monit Assess, 167, 631-641.
[6] Arias, M. E. M., Perez, J. A. G., Vila, F. J. G., Ball, A. (2005). Soil health a new challenge for microbiologists and chemists. Int Microbiol, 8 (1), 13-21.

[7] Barbieri, M. (2016). The importance of enrichment factor (EF) and geoaccumulation index (I geo) the evaluate the soil contamination. Geol Geophysics, 5 (1).

[8] Bern, C. R., Walton-Day, K., Naftz, D. L. (2019). Improved enrichment factor calculations through principal component analysis: Examples from soils near breccia pipe uranium mines, Arizona, USA. Environ. Pollut. 248 (2019), 90-100.

[9] Blaser, P., Zimmermann, S., Luster, J., Shoty, K. W. (2000). Critical examination of trace element enrichment and depletions in soils; $\mathrm{As}, \mathrm{Cr}, \mathrm{Cu}, \mathrm{Ni} \mathrm{Pb}$ and $\mathrm{Zn}$ in Swiss forest soil. Sci Total Environ. 249, 257-280.

[10] Bourennane, H., Douay, F., Sterckeman, T., Villanneau, E., Ciesielski, H., King, D., Baize, D. (2010). Mapping of anthropogenic trace elements inputs in agricultural topsoil from northern France using enrichment factors. Geoderma, 157, $165-174$.

[11] Darko, G., Dodd, M., Nkansah, M. A., Aduse-Poku, Y., Ansah, E., Wemegah, D. D., Borquaye, L. S. (2017). Distribution, and ecological risks of toxic metals in the topsoils in the Kumasi etropolis, Ghana. Cogent Environ. Sci, Jul 25, 3 (1), 1354965.

[12] Desaules A. (2012). Critical evaluation of soil contamination assessment methods for trace metals. Sci Total Environ. 426, $120-131$.

[13] Dragovic, S., Mihailovic, N. (2009). Analysis of mosses and topsoils for detecting sources of heavy metal pollution: multivariate and enrichment factor analysis. Environ Monit Assess. 157 (1-4), 383-390.

[14] Dragun, J., \& Chiasson, A. D. (1991). Elements in North American soils. Greenbelt, Md: Hazardous Materials Control Resources Institute. p. 230.

[15] Frye J. C. and Fent, O. S. (1947). The Late Pleistocene Loesses of Central Kansas. Kansas Geological Survey, Bulletin 70, Part 3.

[16] Hakanson, L. (1980). An ecological risk index for aquatic pollution control, a sediment-ecological approach. Water Res. $14(8), 975-1001$.

[17] Hasan, A. B., Kabir, S., Selim, Reza, A. H. M., Zaman, M. N., Ahsan, A., Rashid, M. (2013). Enrichment factor and geoaccuumulagtion index of trace metals in sediments of the ship breaking area of Sitakund Upazilla (Bhatiary Kumira), Chittagong, Bangladesh. J Geochem Explor. 125, 130-137.

[18] https://serc.carleton.edu/11693. Microbial life Educational Resources. October 15, 2019.

[19] https://www.currentresults.com/Weather/US/average-annual-s tate-precipitation.php. Current Results weather and science facts, 2021.

[20] http://geology.teacherfriendlyguide.org/downloads/mw/tfggm w_8_soils_lr.pdf. Chapter 8: Soils of the Midwestern US.

[21] Huang, S. H., Yang, Y., Yuan, C. Y., Li, Q., Ouyang, K., Wang, B., Wang, Z. X. (2017). Pollution evaluation of Heavy Metals in soil near smelting area by index of Geoaccumulation (I geo). Earth Environ Sci 52, China. 
[22] Ismaeel, W. A., Kusag, A. D. (2015). Enrichment Factor and Geo-accumulation Index for Heavy Metals at Industrial Zone in Iraq. J. Appl. Geol Geophysics (IOSR-JAGG), (2015), 3 (3), p. 26-32.

[23] Izah, S. C., Bassey, S. E., Ohimain, E. (2017). Geoaccumulation index, enrichment factor and quantification of concentration of heavy metals in soil receiving cassava mill effluents in a rural community in the Niger Delt Region of Nigeria. Mol Soil Biol. 8 (2), 7-20.

[24] Jena, V., Ghosh, S., Pande, A., Maldini, K. d., Matic, N. (2019) Geo-accumulation index of heavy metals in pond water sediment of Raipur. Biosci Biotech Res Commun. 12 (3), 585-588.

[25] Jiang, X., Lu, W. X., Zhao, H. Q., Yang, Q. C., Yang, Z. P. (2014). Potential ecological risk assessment and prediction of soil heavy metal pollution around coal gangue dump. Nat Hazard Earth Sys. 14, 1599-1610.

[26] Jiao, X., Teng, Y., Zhan, Y., Wu, J., Lin, X. (2015). Soil heavy metal pollution and risk assessment in Shenyang Industrial District, northeast China. Plos One. 21, 10 (5).

[27] Kabata-Pendias, A. (2010). Trace elements in soils and plants. CRC Press. $4^{\text {th }}$ edition. (p 505).

[28] Kang, Z., Wang, S., Qin, J., Wu, R., Li, H. (2020). Pollution characteristics and ecological risk assessment of heavy metals in paddy fields of Fujian province, China. Sci Rep Nat Res. 10, 12244.

[29] Kang, Z., Wang, S., Qin, J., Wu, R., Li, H. (2020). Pollution characteristics and ecological risk assessment of heavy metals in paddy fields of Fujian province, China. Scientific Reports, 2020, 10: 12244.

[30] Kansas State Soil Harney Silt Loam, USDA, 2006. www.ks.nrcs.usda.gov.

[31] Kong, C., Zhang, S. (2021). Security Regional Division of Farmland Soil Heavy Metal Elements in North of the North China Plain. Front. Environ. Sci. 9: 639460.

[32] Kowalska, J. B., Mazurek, R., Gasiorek, M., Zaleski, T. (2018). Pollution indices as useful tools for the comprehensive evaluation of the degree of soil contamination-A review. Environ Geochem Health. 40, 2395-2420.

[33] Looi, L. J., Aris, A. Z., Yusoff, F. M., Isa, N. M., Haris, H. (2018). Application of enrichment factor, geoaccumulation index, and ecological risk index in assessing the elemental pollution status of surface sediments. Environ Geochem Health (2019) 41: 27-42.

[34] Maina, C. W., Sang, J. K., Raude, J. M., Mutua, B. M. (2019). Geochronological and spatial distribution of heavy metal contamination in sediment from Lake Naivasha, Kenya. $J$ Radiat Res Appl Sci. 2 (1), 37-54.

[35] Maina, D. M., Ndirangu, D. M., Mangala, M. M., Boman, J., Shepherd, K., Gatari, M. J. (2016). Environmental implications of high metal content in soils of a titanium mining zone in Kenya. Environ Sci Pollut R Int. 23 (21), 21431-21440.

[36] Mehr, M. R., Keshavarzi, B., Moore, F., Sharifi, R. (2017). Distribution, source identification and health risk assessment of soil heavy metals in urban area of Isfahan province, Iran. $J$. African Earth Sci. 132 (2017), 16-26.
[37] Mohr, M. R., Keshavarzi, B., Moore, F., Sharifi, R., Lahijanzadeh, A., Kermani, M. (2017). Distribution, source identification and health risk assessment of soil heavy metals in urban areas of Isfahan province, Iran. J. Afr. Earth Sci. 132, 16-26.

[38] Muhs, D. R. (2018). The geochemistry of loess: Asian and North American deposits compared. Journal of Asian Earth Sciences, 155 (2018) 81-115.

[39] Muller, G. (1969). Index of geo accumulation in sediments of the Rhine River. Geo J, 2, 108-118.

[40] Muzerengi, C. (2017). Enrichment and geoacculmualtion of $\mathrm{Pb}, \mathrm{Zn}, \mathrm{As}, \mathrm{Cd}$, and $\mathrm{Cr}$ in soils near new union gold mine, Limpopo Province of South Africa. Mine Water and Circ Econ, 720-727.

[41] National centers for Environmental Information (NOAA) (2017). Formerly the National Climatic Data Center (NCDC). https://www.ncdc.noaa.gov.

[42] Naveedullah, M. Z. H., Chunna, Y., Hui, S., Dechao, D., Chaofeng, S., Liping, L., Yingxu, C. (2013). Risk assessment of heavy metals pollution in agricultural soils of siling reservoir watershed in Zheiiang province, China. BioMed Res Int. 1-10.

[43] Nweke, M. O., \& Ukpai S. N. (2016). Use of enrichment, ecological risk, and contamination factors with geoaccumulation indexes to evaluate heavy metal contents in the soils around Ameka mining area, south of Abakaliki, Nigeria. J Geogr, 5 (4), 1-13.

[44] Odat, S. (2015). Application of Geoaccumulation Index and Enrichment Factors on the Assessment of Heavy Metal Pollution along Irbid/zarqa Highway-Jordan. J. Appl. Sci. 15 (11): 1318-1321, 2015.

[45] Oliveira, M., Usuall, J., Viñas, I., Solsona, C., Abadias, M. (2011). Transfer of Listeria innocua from contaminated compost and irrigation water to lettuce leaves. Food Microbiol. 28 (3), 590-596.

[46] Pierzynski, G. M., Sims, J. T., Vance, G. F. (2005). Soils and environmental quality III. CRC Press. 2-22, 82-127, 334-434.

[47] Poh, S-C., \& Tahir, N. M. (2017). The common pitfall of using enrichment factor in assessing soil heavy metal pollution. Malays J Anal Sci. 21 (1), 52-59.

[48] Proshad, R., Kormoker, T., Islam, M. S., Abu Hanif, M., Chandra, K. (2018). Chronic exposure assessment of toxic elements from agricultural soils around the industrial areas of Tangail district, Bangladesh. Archi. J. Agric. Environ. Sci. 3 (4): 317-336 (2018).

[49] Reiman, C., Caritat, P. D. (2005). Distinguishing between natural and anthropogenic sources of element in the environment: regional geochemical surveys versus enrichment factors. Sci Total Environ. 337 (1-3), 91-107.

[50] Reiman, C., Decarital, P. (2000). Intrinsic flaws of element enrichment factors (EFs) in environmental geochemistry. Envir Sci Tech. 34, 5084-5091.

[51] Saldana-Robles, A., Abraham-Juarez, M. R., Saldana-Robles, A. L., Saldana-Robles, N., Ozuna, C., Gutierrez-Chavez, A. J. (2017). The negative effect of arsenic in agriculture: Irrigation water, soil and crops, state of the art. Applied Ecology and Environmental Research 16 (2): 1533-1551. 
[52] Smith, D. B., Cannon, W. F., Woodruff, L. G., Solano Federico., Kilburn, J. E., \& Fey, D. L. (2013). Geochemical and mineralogical data for soils of the conterminous United States: U.S. Geological Survey Data Series 801, 2013; 19. https://doi.org/10.3133/ds801.

[53] Smith, D. B., Federico Solano., Woodruff, L. G., Cannon, W. F., and Ellefsen, K. J. (2017). Geochemical and mineralogical maps, with interpretation, for soils of the conterminous United States. Scientific Investigations Report 2017-5118. Updated Nov 12, 2019. J Geochem Explor, 154, 49-60.

[54] Soliman, N. F., Nasr, S. M., Okbah, M. A. (2015). Potential ecological risk of heavy metals in sediments from the Mediterranean coast, Egypt. J Environ Health Sci. 10, 13- 70.

[55] Sutherland, R. A., Tolosa, C. A., Tack, F. M. G., Verloo, M. G. (2000). Characterization of selected element concentrations and enrichment ratios in background and anthropogenically impacted roadside areas. Arch Environ Con Tox. 38, 428-438.

[56] Swanson, C. O. (1914). Chemical Analyses of Some Kansas Soils. Kansas State Agricultural College. Agriculture Experiment Station. Bulletin, No. 199.

[57] Szolnoki, Z., Farsang, A., Puskas, I. (2013). Cumulative impacts of human activities on urban garden soil: origin and accumulation of metals. Elsevier Ltd. Environ Pollut. 177, 106-115.

[58] Tepanosyan, G., Sahakyan, L., Belyaeva, O., Maghakyan, N. (2017). Human health risk assessment and riskiest heavy metal origin identification in urban soils of Yerevan, Armenia. Elsevier. Chemosphere. 184, 1230-1240.

[59] Uduma, A. U., \& Awagu, E. F. (2013). Application of Enrichment Factor for assessment of Zinc enrichment and depletion in farming soils of Nigeria. Am J Environ, Energy and Power Research. 1 (8), 166-173.
[60] United States Department of Agriculture. Natural Resources Conservation Service Soils. https://www.nrcs.usda.gov/wps/portal/nrcs/detail/soils/survey/ class/taxonomy.

[61] United States Environmental Protection Agency. Toxics Release Inventory (TRI) Program (2017) Jun 19. www.epa.gov/toxics-release-inventory-tri-program.

[62] United States Natural Library of Medicine (2012). TOXMAP Environmental Health e-Maps. Modified 2020. http://toxmap.nlm.nih.gov.

[63] Varol, M. (2011). Assessment of heavy metal contamination in sediments of the Tigris River (Turkey) using pollution indices and multivariate statistical techniques. J Hazard Mater. 195, 355-364.

[64] Wilson, C. A., Davidson, D. A. (2008). Cresser MS. Multi-element soil analysis: an assessment of its potential as an aid to archaeological interpretation. J Archaeol Sci, 35 (2), 412-424.

[65] Xu, Z. Q., Tuo, X. G., Ni Shijun., Zhang, C. J. (2008). Calculation of heavy metal's toxicity coefficient in the evaluation of potential ecological risk index. Envir Sci Tech. 31 (2), 112-115.

[66] Zhang, H., Chen, J., Zhu, L., Yang, G., Li, D. (2014). Anthropogenic mercury enrichment factors and contributions in soils of Guangdong Province, South China. J Geochem Explor. 144, Part B, 312-319.

[67] Zhu, H-N., Yuan, X-Z., Zeng, G-Z., Iang, M., Liang, J., Zhang, C., Yinj, Huang. H -J., Liu, Z., Jiang, W. (2012). Ecological risk assessment of heavy metals in sediments of Xiawan Port based on modified potential ecological risk index. T Nonferr Metal Soc. 22 (6), 1470-1477. 